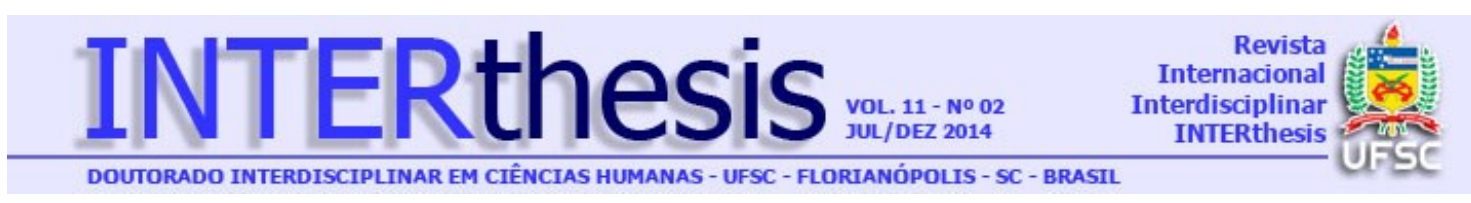

\title{
MANUAL DIAGNÓSTICO E ESTATÍSTICO DE TRANSTORNOS MENTAIS, DSM - 5 ESTATÍSTICAS E CIÊNCIAS HUMANAS: INFLEXÕES SOBRE NORMALIZAÇÕES E NORMATIZAÇÕES
}

\section{Resumo}

Tito Sena ${ }^{1}$

A edição do Manual Diagnóstico e Estatístico de Transtornos Mentais - DSM-5, em 2013, mantém acesa a polêmica sobre diagnósticos psiquiátricos. O campo da psiquiatria, historicamente em disputa com a psicologia e a psicanálise (quanto à forma de avaliação e terapêutica), continua a sustentar uma prática enquadradora classificatória (taxionômica), fundamentada em características e critérios diagnósticos de perturbações ou transtornos verificados, em sua maioria, empiricamente. O uso das ferramentas estatísticas nas ciências humanas é questionável, e o que se pretende neste artigo é apontar o disfarce de critérios quantitativos em critérios qualitativos e, por extensão, da prática discursiva comum de confundir descrições com apreciações, estas últimas com julgamentos valorativos e normativos. Fecha-se um círculo: as frequências (estatísticas) definem as normalidades (axiológicas) e estas se sustentam nas freqüências. Neste âmbito, as elaborações de Canguilhem, Ewald, Foucault e Goffman foram imprescindíveis para a articulação das argumentações teóricas críticas.

Palavras-chave: DSM-5. Estatística. Ciências Humanas. Normalização. Normatização.

\section{INTRODUÇÃO}

O Manual Diagnóstico e Estatístico de Transtornos Mentais, o DSM, em sua quinta edição, foi publicado em maio de 2013 (versão em português - 2014). O guia representa a base para definição de doenças psíquicas, referência para a prática clínica, e segundo seus autores, contém informações úteis para todos os profissionais ligados a saúde mental, "incluindo psiquiatras, outros médicos, psicólogos, assistentes sociais, enfermeiros, consultores, especialistas das áreas

\footnotetext{
1 Doutor em Ciências Humanas pela Universidade Federal de Santa Catarina. Professor do Centro de Ciências Humanas e da Educação da Universidade do Estado de Santa Catarina, Florinaópolis, SC, Brasil. E-mail: titosena06@gmail.com
}

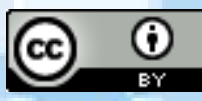

Esta obra foi licenciada com uma Licença Creative Commons - Atribuição 3.0 Não Adaptada.
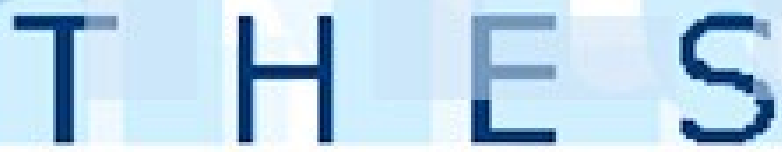
forense e legal, terapeutas ocupacionais e de reabilitação e outros profissionais da área da saúde" (DSM-5, 2014: p.xii)

O título do manual nos fornece elementos para algumas problematizações deste artigo: como aceitar um manual de diagnóstico? Como recorrer à estatística para legitimar a conduta humana? Como manter o dualismo cartesiano corpo-mente na forma eufemística de transtorno mental, quando se sabe que na prática os psiquiatras mantêm a concepção de "doença mental"? Como adotar critérios de avaliação clínica de sintomas, de caráter predominantemente empírico? Segundo o DSM-5,

Um transtorno mental é uma síndrome caracterizada por perturbação clinicamente significativa na cognição, na regulação emocional ou no comportamento de um indivíduo que reflete uma disfunção nos processos psicológicos, biológicos ou de desenvolvimento subjacentes ao funcionamento mental. (DSM-5, 2014; p.20)

A forte ligação dos sistemas de classificação psiquiátrica com as medidas estatísticas é explicitamente manifestada, valorizada e reconhecida pelos autores do DSM-5, empreendimento conjunto elaborado por mais de mil consultores, sessenta entidades profissionais, de trinta e nove países, coordenado pela American Psychiatric Association²:

O uso de testes de campo para demonstrar confiabilidade de forma empírica foi um aprimoramento significativo introduzido no DSM-III. A elaboração e a estratégia de implementação de Testes de Campo do DSM5 representam várias mudanças relativas à abordagem utilizada no DSM-III e no DSM-IV, particularmente na obtenção de dados sobre a precisão de estimativas de confiabilidades kappa (uma medida estatística que avalia o nível de concordância entre avaliadores que corrige para concordâncias ao acaso devido a taxas de prevalência) no contexto de ambientes clínicos com níveis elevados de comorbidade diagnóstica. (DSM-5, 2014: p.07) (grifos meus).

Esta aliança psiquiatria-estatística é antiga. Nos últimos cento e sessenta anos, o número de descrições de categorias diagnósticas passou de uma idiotismo/insanidade - em 1840, para 300 categorias em 2013 com o DSM-5. Conforme informação no anterior DSM-IV de 1994, com texto revisado em 2000 :

Poder-se-ia considerar como sendo a primeira tentativa de coletar informações sobre doença mental o registro de uma categoria, a saber, a de

\footnotetext{
${ }^{2}$ A APA, American Psychiatric Association foi fundada em 1844 e reúne hoje mais de 35.000 médicos psiquiatras, especialistas no diagnóstico e tratamento de doenças mentais. (Fonte: http://www.psychiatry.org/about-apa--psychiatry)
}

R. Inter. Interdisc. INTERthesis, Florianópolis, v.11, n.2, p.96-117, Jul-Dez. 2014
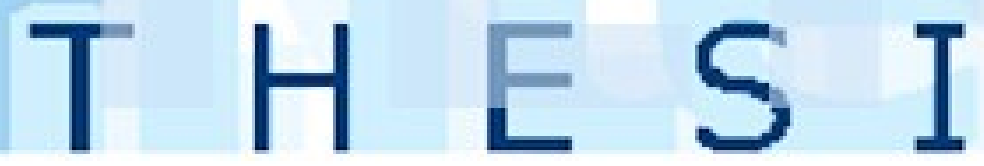
"idiotismo/insanidade", no censo de 1840. No censo de 1880 foram identificadas sete categorias de doença mental - mania, melancolia, monomania, paresia, demência, dipsomania e epilepsia (DSM-IV, 2002, p. 22).

O DSM-I, primeiro manual oficial da APA, surgiu em 1952 com 106 diagnósticos psiquiátricos; o DSM-II em 1968 apresentava 182 diagnósticos, o DSMIII, publicado em 1980, continha 265 diagnósticos e sua revisão em 1987, estendeuse para 292 diagnósticos. O DSM-IV foi editado em 1994, com 297 diagnósticos e o recém publicado DSM-5, de 2013, apresenta 300 categorias (número questionável) ${ }^{3}$.

Mas no início do rastro desta crescente desmesurada de diagnósticos, podese considerar, sem entrar em maiores detalhes, a Segunda Guerra Mundial como o evento que induziu e acelerou as pesquisas nesta área, seja pelas condições dos combatentes, de choque psicológico, ou de seus efeitos no pós-guerra. O aumento do número de internações psiquiátricas, paralelamente ao surgimento de novos quadros de "doenças", levou a APA a reavaliar as nomenclaturas das desordens e transtornos mentais existentes e a redimensionar o campo teórico, metodológico, terapêutico e assistencial da psiquiatria.

Neste contexto ocorreu o lançamento do DSM-I, em 1952, e não por acaso também coincidiu com a introdução dos tranquilizantes na prática psiquiátrica, inaugurando a era do método químico para tratamento (ou controle?) dos pacientes psiquiátricos. Como consequência, um novo campo se configurou e se fortaleceu ao longo das décadas subsequentes, a Psicofarmacologia, o estudo dos medicamentos específicos para tratamento das doenças mentais. O psiquiatra John Cade (19121980) já efetuava tratamento da mania com lítio, em 1949; os efeitos antipsicóticos da clorpramazina foram descobertos em 1952 por Jean Delay (1907-1987) e Pierre Deniker (1917-1998); os primeiros ansiolíticos foram o meprobamato (1954) e o clordiazepóxido (1957), seguidos pelos benzodiazepínicos. Os antidepressivos foram introduzidos por David Crane, em 1956, e Nathan Kline, em 1958, na forma de iproniazida.

\footnotetext{
${ }^{3}$ Este é o número levantado para todas as codificações categorizadas, mas é controverso, pois a APA utiliza, às vezes, codificações repetidas para transtornos diferentes. Dependendo do critério adotado para contagem, pode-se encontrar até 356 diagnósticos, Outro elemento para alterar a quantificação são as figuras do Outro Transtorno Especificado e Transtorno Não Especificado, termos adotados para classificação onde não é possível o enquadramento segundo os critérios padronizados. Convém destacar: os códigos do DSM-5 possuem correspondências numéricas (de F00.0 até F99) no CID-10, Classificação Estatística Internacional de Doenças, adotado pela OMS.
}

R. Inter. Interdisc. INTERthesis, Florianópolis, v.11, n.2, p.96-117, Jul-Dez. 2014
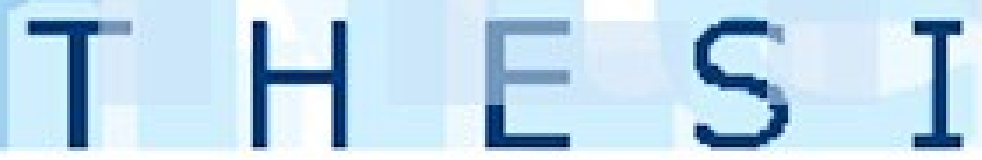
A descoberta, na década de 50 , dos efeitos do lítio, dos antipsicóticos, dos antidepressivos e sua disseminação, modificaram os métodos de tratamento e representaram uma ruptura em relação aos hospícios do século XVIII ${ }^{4}$ e as práticas correlatas de internamento, isolamento e acorrentamento, ou em relação aos tratamentos de eletrochoque ${ }^{5}$ ou as lobotomias ${ }^{6}$ do início do século $\mathrm{XX}$.

Iniciou-se, deste modo, a expansão da prática da medicação nos espaços institucionais e nos consultórios particulares. A indústria farmacêutica (sem que esta constatação signifique sua demonização) obteve novos tipos de consumidores, se não o portador de depressão ${ }^{7}$, o portador de ansiedade ${ }^{8}$, ou o ambíguo portador do transtorno afetivo bi-polar ${ }^{9}$ (ex-PMD: psicose maníaco-depressiva), duplo consumidor pendular destes medicamentos. O impacto da introdução dos psicofármacos pôde (e pode) ser medido na redução considerável na admissão hospitalar e/ou na permanência de pacientes psiquiátricos nas instituições de saúde. Por outro lado, o alinhamento entre os interesses da indústria farmacêutica e os diagnósticos dos manuais DSM possibilita levantar suspeitas sobre o uso abusivo ou descontrolado dos medicamentos utilizados nos tratamentos psiquiátricos.

O campo da psiquiatria, historicamente em disputa com a psicologia e a psicanálise (quanto à avaliação e à terapêutica), com o DSM-5, continua a sustentar uma prática enquadradora classificatória (taxionômica). O compêndio-guia é fundamentado em características e critérios diagnósticos de perturbações ou transtornos, verificados, em sua maioria, empiricamente através de recenseamento em hospitais e institutos psiquiátricos, centros clínicos, estudos de associações

\footnotetext{
4 O médico francês Philippe Pinel (1745-1826) foi um dos responsáveis pela humanização no tratamento da "loucura", abolindo sangrias, purgações e correntes, adotando terapias de diálogo, ocupacionais e morais, não rompendo, entretanto, com as práticas de internamento.

${ }^{5}$ A eletroconvulsoterapia, nome técnico do eletrochoque foi desenvolvida pelos italianos Ugo Cerletti (1877-1963) e Lucio Bini (1908-1964), em 1938.

${ }^{6}$ A lobotomia ou leucotomia frontal foi introduzida pelo médico português Egas Moniz (1874-1955) em 1935, e consistia numa intervenção cirúrgica no cérebro, no qual se seccionavam os feixes de fibras nervosas entre as regiões frontais e o tálamo, suprimindo a agitação crônica e a obsessão. Moniz, pela técnica, chegou a ganhar em 1949, o Nobel de Medicina e Fisiologia. Após 20 anos esta prática caiu em desuso.

${ }^{7}$ Para estes há os antidepressivos inibidores seletivos, recaptadores de serotonina, as drogas da família do Prozac: fluoxetina, sertralina, paroxetina e fluvoxamina. Fontes sobre o ação dos medicamentos psiquiátricos são Cordioli (1997), Bertolote (1997) e Pontes (1998), entre outros.

${ }^{8}$ Os medicamentos contra a ansiedade, conhecidos como ansiolíticos, com poder sedativo/hipnótico, incluem os benzodiazepínicos e os barbitúricos.

${ }^{9}$ São prescritos pelos psiquiatras aos bi-polares os estabilizadores de humor olanzapina, risperidona e a quetiapina.
}

R. Inter. Interdisc. INTERthesis, Florianópolis, v.11, n.2, p.96-117, Jul-Dez. 2014
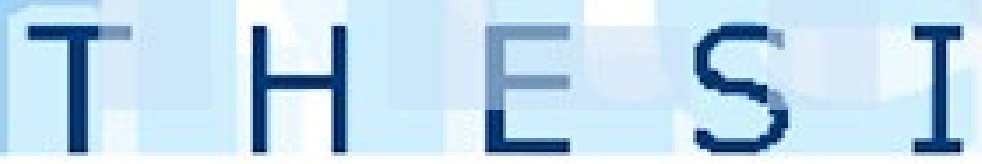
médicas, práticas clínicas e pesquisas. Para os autores, "O DSM-5 também é instrumento para a coleta e a comunicação de estatísticas de saúde pública sobre as taxas de morbidade e mortalidade dos transtornos mentais" (DSM-5, 2014, p.xii).

Com base nestas considerações, descreveremos um pouco da história da estatística e sua consolidação como ciência aplicada, contrapondo algumas críticas à sua apropriação pelas ciências humanas.

\section{A ESTATÍ́STICA COMO CIÊNCIA APLICADA}

A etimologia da palavra estatística pode partir da expressão em latim statisticum collegium - palestra sobre os assuntos do estado -, por sua vez com origem em três raízes: status, palavra que em latim significa estado ou situação; statista, palavra que em italiano significa homem de Estado, estadista ou político; e Staat e statistik, palavras alemãs que significam Estado, designando a análise de dados sobre o Estado. Foi o economista alemão Gottfried Achenwall (1719-1772), no século XVIII, quem introduziu, em 1746, a palavra "estatística" nos domínios demográficos e econômicos, com a produção e sistematização de tabelas descritivas de uma situação, sem, entretanto, realizar um tratamento efetivamente matemático, estatístico-probabilístico. Ainda no século XVIII, o matemático, filósofo, professor, enciclopedista e político revolucionário francês Jean Marie Antoine Nicolas de Caritat, Marquês de Condorcet (1743-1794), publicou livros de probabilidades e cálculo integral que o destacaram como um dos pioneiros da matemática social.

No século XIX, coube ao belga, matemático e físico, Lambert Adolphe Jacques Quételet (1796-1874) lançar a teoria e o conceito de homem médio, embasada na noção de probabilidade e de distribuição normal. Desta maneira, os esquemas probabilísticos da Teoria de Análise das Probabilidades de Pierre Simon Laplace (1749-1827) foram estendidos ao método estatístico, fazendo surgir então sua noção atual, de estatística como análise das observações em população pertencente a um mesmo conjunto, para pôr em evidência certas propriedades, apresentadas em resultados numéricos enquadrados com uma margem de erro associada a certa probabilidade.

R. Inter. Interdisc. INTERthesis, Florianópolis, v.11, n.2, p.96-117, Jul-Dez. 2014
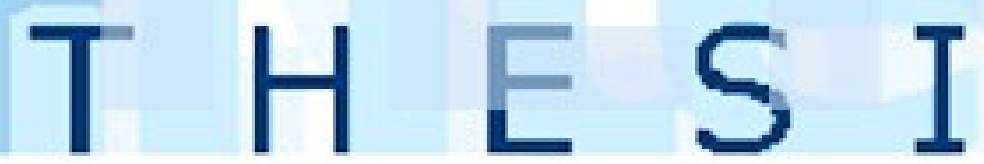
Pode-se afirmar que a Estatística divide-se em Estatística Descritiva, área em que se utilizam procedimentos para organizar e apresentar dados de forma conveniente e comunicativa; e em Inferência Estatística, para procedimentos empregados para chegar a grandes conclusões ou inferências sobre populações, com base em dados amostrais (Barros, Fischer \& Associados, 2005).

O tratamento estatístico ${ }^{10}$ envolve o entrelaçamento de algumas etapas básicas: escolha da amostragem, coleta de dados, mensuração, tabulação, cálculos, descrição e resumo dos resultados, interpretação dos dados e/ou resultados amostrais. A teorização probabilística é efetuada quando se deseja uma predição; a inferência estatística é, desta forma, utilizada para uma estimação. Inicialmente, o conceito de probabilidade era de caráter frequentista, ou seja, a probabilidade de um acontecimento era associada à frequência com que ele se repetia quando observadas (empirismo) em um grande número de experiências. Atualmente, a probabilidade, chamada de esperança matemática, será a medida da possibilidade de obter certo resultado.

A análise das variáveis quantitativas é feita com as medidas de tendência central ou de posição, caracterizadas pelos parâmetros: média aritmética, mediana, moda de dados agrupados e não agrupados, quartis, decis e percentis. As medidas de dispersão ou de variabilidade são caracterizadas pelos parâmetros: desvio médio, variância, desvio-padrão, coeficiente de variação e amplitude nodal. Os dados e resultados são expostos através de representação tabular ou em gráficos (barras, histogramas), além de curvas de frequência (acumulada, simétrica e assimétrica). Na famosa curva de Gauss, a distribuição é do tipo simétrico em torno da média, resultante num desenho em forma de sino.

É a partir dos resultados estatísticos que se efetua a técnica das inferências, ou seja, estendem-se os resultados e os conhecimentos adquiridos pela observação da amostra para toda a população, com certa margem de erro. Este procedimento, a inferência, talvez seja o ponto mais controvertido da estatística, pela pretensão de extrapolar as frequências e as conclusões de uma amostra para toda a população, mesmo que as classificações tenham origem num único recorte temporal (sincrônica).

10 Sobre tratamento estatístico, utilizou-se fontes de Barbetta(1998), Barros, Fischer \&Associados(2005) Dancey\&Reidy (2006), Davis (1976), Vieira (1991), Wada\&Vieira(1987), Dorsch(1978), entre outros.

R. Inter. Interdisc. INTERthesis, Florianópolis, v.11, n.2, p.96-117, Jul-Dez. 2014 
A estatística obteve influências de uma corrente social, representada por Adolphe Quételet, com seus estudos públicos de estimativas de nascimentos e população na primeira metade do século XIX, e de uma corrente biológica, representada por Francis Galton e seus estudos eugenistas, na segunda metade do mesmo século.

Francis Galton, responsável pelas bases da estatística como ciência aplicada, fundou, em 1907, a Sociedade Britânica de Eugenia, que, durante alguns anos, abrigou o Instituto de Estatística, desenvolvendo questionários e métodos de pesquisa para coleta de dados, censos escolares, estudos sobre gêmeos, sobre ancestralidade, inteligência e diferenças individuais. A partir de seu trabalho, tudo passou a ser medido, com o objetivo de estabelecer uma ordem de hierarquia biométrica e antropométrica de classificação humana (por ex., cor da pele).

Por outro lado, a taxionomia (ciência da classificação), especialmente da botânica e da zoologia, consolidada pela biologia naturalista darwinista, estendeu suas aplicações a outros campos das ciências e, ao se unir com a matemática, passou a servir ao propósito estratégico de quaisquer ciências para confirmar, alterar, romper ou manter algum enquadramento.

O critério básico de verificabilidade confirmacionista ou de falseabilidade baseado, em equações matemáticas, e a transposição destes recursos para as ciências humanas, são duramente atacados por Foucault:

A matemática foi seguramente modelo para a maioria dos discursos científicos em seu esforço de alcançar o rigor formal e a demonstratividade; mas para o historiador que interroga o devir efetivo das ciências, ela é um mau exemplo - um exemplo que não se poderia, de forma alguma, generalizar." (FOUCAULT,1995: p.214)

Apesar de considerar a matemática uma ciência única, o alerta de Foucault é para o risco de homogeneizar todas as formas singulares de historicidade, além de estabelecer limites rígidos e fixos. Segundo o pensador francês, [...] o recurso às matemáticas, sob uma forma ou outra, sempre foi a maneira mais simples de emprestar ao saber positivo sobre o homem um estilo, uma forma, uma justificação científica." (FOUCAULT,1999: p.485).

A adoção de tabelas, gráficos com percentuais, levantamentos estatísticos e de dados matemáticos, é uma constante em estudos e pesquisas, levantamentos e enquetes, sendo uma continuidade do século XX e XXI, fruto, evidentemente, de 
uma tradição cientificista de nossa sociedade, que busca, nestas estatísticas, confirmações ou negações para as práticas da população. Como consequência, sustentam os padrões de normalidade e produzem normatizações, sejam de posturas, como de atitudes, condutas, costumes, comportamentos e desejos, através de um "verniz" científico.

Esta também é a lógica do DSM-5 - Diagnóstico e Estatístico de Transtornos Mentais, pois com seus critérios diagnósticos, especificadores, características diagnósticas, sintomas, marcadores, percentuais de prevalência e prognósticos, formula em suas linhas, descrições de psicopatologias e transtornos mentais, codificados não apenas no sentido numérico, mas também no sentido normalizador.

Embora o objetivo deste artigo não tenha sido analisar as mudanças do DSM5, o novo compêndio traz, por exemplo, entre outras novidades: o Transtorno de Acumulação (código 300.3) como um transtorno obsessivo-compulsivo caracterizado pela dificuldade persistente de se desfazer de pertences; e Disforia de Gênero (código 302.6), como um diagnóstico global de incongruência acentuada entre o sexo experimentado/expresso e o gênero designado de uma pessoa.

Estes exemplos, e muitos outros, nos fazem refletir sobre o que é normal e anormal, patológico e saudável, doença e saúde, doença mental e saúde mental e sobre a ideologia subjacente à formulação, formatação e adoção dos compêndios empíricos DSMs produzidos pela psiquiatria.

\section{ALGUMAS INFLEXÕES CONCEITUAIS SOBRE A NORMA E O NORMAL}

Uma das reflexões milenares é o constante pensar e o repensar as intrarrelações de uma sociedade com seus seres diferentes. Para refletir sobre este diferente, o outro, encontraremos pressupostos, concepções e raízes epistemológicas em várias designações, mas duas, em especial, são alvo de nosso interesse: o normal e o patológico, ou, em seus antônimos, o anormal e o saudável.

Etimologicamente, norma deriva do latim norma, princípio, preceito, regra, e, normal, de normalis, que está em conformidade com a norma, regular, comum. Mas norma também significa esquadro, ângulo normal, ângulo de $90^{\circ}$ e, por extensão, quando algo está no esquadro se diz que está normal, perpendicular, ortogonal, correto. Pode-se entender por que quando algo é dito torto, está fora do esquadro,

R. Inter. Interdisc. INTERthesis, Florianópolis, v.11, n.2, p.96-117, Jul-Dez. 2014
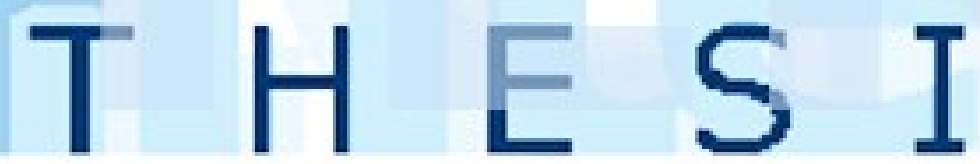
não é normal. A partir destas definições, podemos aceitar, num primeiro momento, que "normatizar" é prescrever normas, condutas, regras, preceitos, regulamentos, instruções normativas, enquanto "normalizar" significa tornar algo "normal", ou seja, de acordo com estas regras.

Normatização e normalização, entretanto, apresentaram incorporações históricas, com deslocamentos e re-conceitualizações de várias áreas. Em matemática, em física, em química, em fisiologia, em antropologia, em sociologia, em psicologia, norma e normal possuem acepções próprias, algumas próximas, outras distantes. Esta discussão não é simples e é antiga, mas atendo-nos ao período das formações científicas disciplinares, ou ao século XIX, encontramos em um dos fundadores da sociologia, o francês Émile Durkheim (1858-1917), as referências iniciais sobre o tema de nosso vetor de fundamentação, com as proposições de Georges Canguilhem e Michel Foucault.

Para Durkheim, um determinista social, influenciado pelo evolucionismo, a sociedade molda as ações das pessoas e as recompensa à medida que desempenham seus papéis sociais. Se estas pessoas tentam contrariar a sociedade, esta aciona controles e coerções. Em seu livro de 1895, As Regras do Método Sociológico, Durkheim reserva o capítulo terceiro às "Regras relativas à distinção entre o normal e o patológico":

\begin{abstract}
Chamaremos normais aos fatos que apresentam as formas mais gerais e daremos aos outros o nome de mórbidos ou de patológicos. Se convencionarmos chamar de tipo médio ao ser esquemático que resultaria da reunião num todo, numa espécie de individualidade abstrata, das características mais freqüentes na espécie com as suas formas mais freqüentes, poder-se-á dizer que o tipo normal se confunde com o tipo médio, e que qualquer desvio em relação a este padrão da saúde é um fenômeno mórbido (DURKHEIM, 2003: p.74). (grifos meus)
\end{abstract}

Observa-se em Durkheim, além de uma presença direta do critério positivista de Auguste Comte (1789-1857), uma correlação associativa entre o padrão de frequência, média e normalidade e a definição de seu oposto, o desviante, o anormal, o mórbido, o patológico. Ao comparar o estudo dos sociólogos com o dos fisiologistas que estudam as funções do organismo médio, Durkheim define que "um ato social não pode, pois, ser considerado normal para uma espécie social determinada senão em relação a uma fase, igualmente determinada, do seu desenvolvimento" (DURKHEIM, 2003, p. 75). Esta citação é mencionada por Michel

R. Inter. Interdisc. INTERthesis, Florianópolis, v.11, n.2, p.96-117, Jul-Dez. 2014
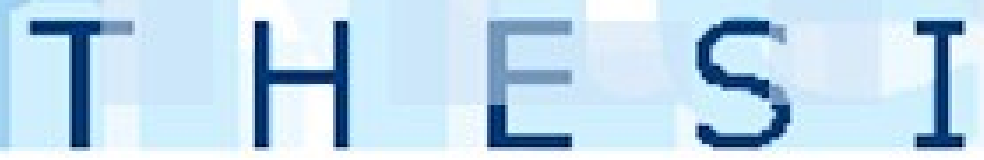
Foucault em Maladie Mentale et Psychologie (Doença Mental e Psicologia), para elaborar análises sobre as concepções estatísticas e evolucionistas e apontar suas implicações antropológicas. Referindo-se à antropóloga norte-americana Ruth Benedict (1887-1948), autora de Padrões de Cultura (1934), segundo a qual cada cultura formará uma imagem virtual da doença, delineada por padrões de exclusão ou aceitação (e até privilégio), Foucault se contrapõe às duas análises - as de Durkheim e de Benedict -, por entender que ambas apresentam uma visão negativa de doença.

É deixar de lado, sem dúvida, o que há de positivo e de real na doença, tal como se apresenta numa sociedade. Há, de fato, doenças que são reconhecidas como tais, e que têm, no interior de um grupo, status e função; o patológico não é mais então, em relação ao tipo cultural, um simples desvio; é um dos elementos e uma das manifestações deste tipo. (FOUCAULT, 1994: p.73). (grifos meus)

O filósofo e epistemólogo Georges Canguilhem (1904-1995), em sua obra O Normal e o Patológico (1966), explora rigorosamente a história dos conceitos médicos (normal e patológico) desenvolvidos na fisiologia e biologia no decorrer dos séculos XIX e XX. No século XIX, a medicina era considerada como ciência das doenças e a fisiologia, como ciência da vida; mas com os trabalhos do fisiologista francês Claude Bernard (1813-1878), principalmente com sua Introdução ao Estudo da Medicina Experimental (1865), a medicina passou a desenvolver uma abordagem quantitativa entre o normal (saúde) e o patológico (doença). Para Canguilhem, os fenômenos patológicos são idênticos aos correspondentes fenômenos normais, salvo pelas variações quantitativas, de modo que a explosão de diagnósticos na medicina se constituiu às expensas de um processo, adotado ao longo do século XIX, de patologização do normal. Em seu trabalho (originalmente na tese de doutorado em 1943), inicia reflexões epistemológicas com a afirmação-tese a partir da qual desenrola sua argumentação histórica e filosófica.

\footnotetext{
Essa evolução resultou na formação de uma teoria das relações entre normal e patológico, segundo a qual os fenômenos patológicos nos organismos vivos nada mais são que variações quantitativas, para mais ou para menos, dos fenômenos fisiológicos correspondentes. Semanticamente, o patológico é designado a partir do normal, não tanto como a ou dis, mas como hiper ou hipo. Essa teoria não defende absolutamente a tese de que saúde e doença sejam opostos qualitativos, forças em luta, [...]. A convicção de poder restaurar cientificamente o normal é tal, que acaba por anular o patológico (CANGUILHEM, 1995, p. 22, grifos meus).
}

R. Inter. Interdisc. INTERthesis, Florianópolis, v.11, n.2, p.96-117, Jul-Dez. 2014
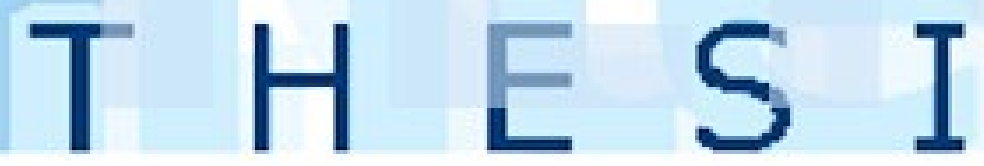
Ao longo do seu texto, Canguilhem promove um constante e provocante exercício de ambiguidade, centrado na distorção conceitual promovida pela medicina, principalmente entre o normal e o patológico, entre a doença e a anomalia.

A doença seria mera perturbação do equilíbrio do corpo, ou é também esforço da natureza agindo sobre o homem para obter novo equilíbrio?

Isto conduz a duas concepções terapêuticas, a interventora (técnica médica) e a espontânea (cura por si próprio). Continuando neste raciocínio - partindo dos dois sentidos da palavra, "é normal aquilo que é como deve ser; e é normal, no sentido mais usual da palavra, o que se encontra na maior parte da espécie determinada ou o que constitui a média ou o módulo de uma característica mensurável" (CANGUILHEM, 1995, p. 95) - efetua-se uma colagem associativa ao incluir um valor de julgamento em que a perfeição, a partir do comum, é o ideal. Na medicina, por exemplo, o estado normal é o estado habitual e, ao mesmo tempo, o estado ideal.

É certo que, em medicina, o estado normal do corpo, é o estado que se deseja restabelecer. Mas será que se deve considerá-lo normal porque é visado como fim a ser atingido pela terapêutica, ou, pelo contrário, será que a terapêutica o visa justamente porque ele é considerado como normal pelo interessado, isto é, pelo doente? Afirmamos que a segunda é a verdadeira. Achamos que a medicina existe como arte de vida porque o vivente humano considera, ele próprio, como patológicos - e devendo portanto serem evitados ou corrigidos - certos estados ou comportamentos que, em relação à polaridade dinâmica da vida, são apreendidos sob forma de valores negativos. Achamos que, desta forma, o vivente humano prolonga, de modo mais ou menos lúcido, um efeito espontâneo, próprio da vida, para lutar contra aquilo que se constitui um obstáculo à sua manutenção e a seu desenvolvimento tomados como normas. (CANGUILHEM, 1995, p. 96, grifos meus).

Canguilhem, assim, nos possibilita compreender a ânsia dos enquadramentos e os desejos ou necessidades de normalidade sentida por pessoas em dúvida sobre sua condição ou estado, tendo por referência o que consideram normal.

Outro conceito do autor, de fundamental importância para entendimento das influências de enquetes e inquéritos comportamentais na produção de subjetividades, é o de anomalia. A palavra anomalia também tem dubiedade etimológica: anomalia vem do grego an-omalos, desigualdade, irregularidade, e pode derivar de a-nomos, anomia, estado caracterizado pela ausência de leis (nomos=lei), de regras, de normas. A proximidade do grego nomos (lei) e da norma latina, por situações históricas, ocasionaram uma sobreposição conceitual. Para 
Canguilhem, entretanto, ocorreu um engano, um erro de etimologia que gerou uma confusão,

Assim, com todo o rigor semântico, anomalia designa um fato, é um termo descritivo, ao passo que anormal implica referência a um valor, é um termo apreciativo, normativo, mas a troca de processos gramaticais corretos acarretou uma colusão dos sentidos respectivos de anomalia e de anormal. Anormal tornou-se um conceito descritivo e anomalia tornouse um conceito normativo. (CANGUILHEM, 1995, p. 101, grifos meus).

Esta inversão conceitual contribuiu por definir critérios médicos para definir diagnósticos pautados em anomalias e anormalidades. Não apenas diagnósticos, mas descrições de variações individuais, de tal modo que as anomalias passaram a ser classificadas hierarquicamente, conforme sua complexidade, de leves até graves. Os estudos teratológicos, preocupações do século XIX, eram estudos de monstruosidades, anomalias muito complexas, envolvendo malformações orgânicas.

$\mathrm{Na}$ esteira destas confusões, anormalidade e anomalia consistem em se afastar, por comparação, da grande maioria dos indivíduos de uma espécie, ou seja, um desvio estatístico. Por este raciocínio, conclui-se que anomalia não é da esfera da patologia, do estudo das doenças, sendo pathos, em grego, sentimento de sofrimento. O patológico é o que provoca sofrimento no indivíduo e anormal é aquilo que se desvia consideravelmente da média estatística. Entretanto, diversidade não é doença. Um gênio excepcional ou filhos sêxtuplos são raríssimos, mas não são fenômenos patológicos (mórbidos), ou seja, o anormal não é patológico. Esta última afirmação, entretanto, é negada, pois o anormal e as anomalias se tornaram patológicas:

\begin{abstract}
Sem dúvida há uma maneira de considerar o patológico como normal, definindo o normal e o anormal pela freqüência estatística relativa. Em certo sentido, pode-se dizer que uma saúde perfeita contínua é um fato anormal. Mas é que existem dois sentidos da palavra saúde. A saúde considerada de modo absoluto é um conceito normativo que define um tipo ideal de estrutura e de comportamento orgânicos; neste sentido é um pleonasmo falar em perfeita saúde, pois a saúde é o bem orgânico. A saúde adjetivada é um conceito descritivo que define uma certa disposição e reação de um organismo individual em relação às doenças possíveis. Os dois conceitos, descritivo qualificado e normativo absoluto são tão distintos que mesmo o homem do povo diz que seu vizinho tem má saúde ou que ele não tem saúde, considerando como equivalentes a presença de um fato e a ausência de um valor. Quando se diz que a saúde continuamente perfeita é anormal, expressa-se o fato da experiência do ser vivo, incluir, de fato, a doença (CANGUILHEM, 1995, p. 106-7, grifos meus).
\end{abstract}

Neste jogo de vocábulos e transposições conceituais, Canguilhem prossegue afirmando que a anomalia pode se transformar em doença, formulando uma

R. Inter. Interdisc. INTERthesis, Florianópolis, v.11, n.2, p.96-117, Jul-Dez. 2014
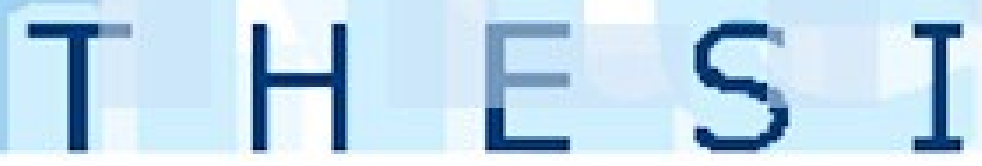
equação entre anormal, anomalia e doença. A medicina passa a considerar tanto doença quanto anomalia (de caráter descritivo), como conceitos normativos, ao aplicar julgamento de valor a estes estados.

De maneira similar, em Foucault, um conjunto de termos nucleados em torno da palavra norma é recorrente: normalidade, normalização, normatização e outros correlatos, como poder normativo, sanção normalizadora, disciplina, vigilância hierárquica, etc. Aparecem com tal intensidade que seu amigo, e assistente durante vários anos no Collége de France, o filósofo François Ewald, em Foucault: a Norma e o Direito, reserva a segunda parte de seu livro para descrever este aspecto da produção foucaultiana: a instituição de uma ordem normativa, característica das relações de poder e saber. A partir de suas análises, Ewald (2000) conclui:

O que é uma norma? Um princípio de comparação, de comparabilidade, uma medida comum, que se institui na pura referência de um grupo a si próprio, a partir do momento em que só se relaciona consigo mesmo, sem exterioridade, sem verticalidade (EWALD, 2000, p. 86).

Ewald prossegue com a aplicação do cálculo das probabilidades às ciências humanas e com o quanto, para o estatístico, isto representa de redução de significações dos fatos. Melhor dizendo, o sentido deriva de pura factualidade e o número faz sentido por si mesmo, razão pela qual o mundo se reduz a mero agrupamento de dados.

\begin{abstract}
Precisamente por este tipo de pensamento, a realidade de um facto cresce com a multiplicidade das suas ocorrências. A massa o número fazem a existência. Inversamente, um acontecimento singular, excepcional, contará tanto menos quanto a sua freqüência é, em princípio, nula. $\mathbf{O}$ cálculo das probabilidades funciona como uma astúcia da razão: se as causas são desconhecidas, bem devem traduzir-se pelos seus efeitos. [...] Os factos são ordenados por categorias. Possuem nomes: nascimento, morte, acidente, suicídio, avaliação. Mas de acordo com um uso rigorosamente nominalista da categoria. Porque a categoria se encontra inteiramente dispersa nos factos que agrupa, nas pequenas unidades discretas que vêm dispor-se nela (EWALD, 2000, p. 92, grifos meus).
\end{abstract}

Quase uma constante explícita, ou pelo menos como pano de fundo para suas formulações, Foucault, de uma maneira ou outra, retoma o papel da norma e da disciplina na produção real de um indivíduo, e sempre a partir de campos atravessados por "desviantes" destas normas: a loucura dos loucos nos hospícios dos psiquiatras, a criminalidade dos delinquentes nas prisões dos juízes, as doenças dos doentes nos hospitais dos médicos, a sexualidade dos pervertidos sexuais nos

R. Inter. Interdisc. INTERthesis, Florianópolis, v.11, n.2, p.96-117, Jul-Dez. 2014
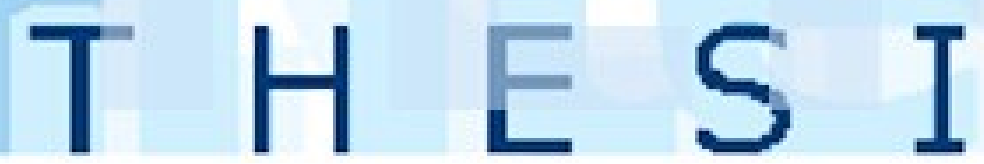
consultórios dos sexólogos. Pode-se, porém, afirmar que é nas obras Vigiar e Punir e em História da Sexualidade I que está presente, em especial, o modo de funcionamento das normas modernas: a normalização, como técnica, como prática, como saber e como discurso.

Referindo-se à relação entre disciplina e punição nas escolas, nas oficinas e nos quartéis, em Vigiar e Punir, publicado em 1975, Foucault afirma que o castigo disciplinar, surgido nos séculos XVII e XVIII, tem a função de reduzir os desvios e repartir os grupos em classificações hierarquizadas com uma divisão extremada em "honoríficas" e "vergonhosas".

\begin{abstract}
Medir em termos quantitativos e hierarquizar em termos de valor as capacidades, o nível, a "natureza" dos indivíduos. Fazer funcionar, através desta medida "valorizadora", a coação de uma conformidade a realizar. Enfim traçar o limite que definirá a diferença em relação a todas as diferenças, a fronteira externa do anormal (a "classe vergonhosa" da Escola Militar). A penalidade perpétua que atravessa todos os pontos e controla todos os instantes das instituições disciplinares compara, diferencia, hierarquiza, homogeniza, exclui. Em uma palavra, ela normaliza. (FOUCAULT, 1987: p.152-3) (grifos meus)
\end{abstract}

O uso das ferramentas estatísticas nas ciências humanas é polêmico, mas, a partir das considerações e aportes anteriores, o que se pretende com esta argumentação é apontar o disfarce de critérios quantitativos em critérios qualitativos e, por extensão, da prática discursiva comum de confundir descrições com apreciações, estas últimas com julgamentos valorativos e normativos. Fecha-se um círculo: as frequências (estatísticas) definem as normalidades (axiológicas) e estas se sustentam nas frequências.

A questão não é apenas da extrapolação de limites estatísticos, com seus cálculos de curva de distribuição normal, média $(\mu)$ e desvio padrão $(\sigma)$, para as ciências humanas. Os matemáticos Pierre Simon Laplace (1749-1827) e Johan Karl Gauss (1777-1855), ao elaborar a curva Laplace-Gauss, não podem ser acusados de ter inventado o conceito estigmatizante de desviante, aquilo que desvia do desvio-padrão, que foge da curva normal, o anormal. Parece jogo de palavras, mas o próprio conceito de desvio-padrão sofreu um desvio fora do padrão, ao ser transposto para as ciências humanas.

R. Inter. Interdisc. INTERthesis, Florianópolis, v.11, n.2, p.96-117, Jul-Dez. 2014
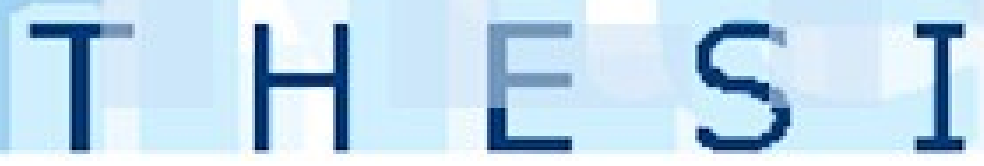
Numa leitura foucaultiana, tanto a normatização, como formas de saber, quanto a normalização, como forças do poder, são fixações enquadradoras, cujos processos se consolidaram no século XIX e prosseguiram no século XX.

Podemos relacionar diversos estudiosos do enquadramento no final do século XIX: Francis Galton (1822-1911), fundador do movimento eugênico, pai da biometria (medidas biológicas) e precursor da psicometria, utilizando o inquérito pioneiro sobre formação de imagens mentais; o psiquiatra Benedict Morel (1808-1873), com a teoria da degenerescência, colocando a criminalidade e a doença mental em termos de racismo biológico (étnico); Cesare Lombroso (1835-1909), criminologista italiano com seus biotipos criminais de raça e hereditariedade e sua teoria antropométrica do criminoso nato (em O homem criminoso, 1876) e, na área da sexualidade, Richard von Kraft-Ebing (1840-1902), pioneiro na classificação e sistematização dos desvios sexuais, no livro Psychopathia Sexualis (1886).

Todos estes estudiosos, de uma maneira ou outra, foram influenciados por três personagens do século XIX: pelo naturalista Jean-Baptiste Lamarck (17441829), um dos primeiros defensores da teoria de evolução das espécies animais, através da transmissão de caracteres adquiridos (pelo uso ou desuso) aos descendentes; por Gregor Mendel (1822-1884), com as leis de transmissão dos caracteres genéticos e hereditários; e por Charles Darwin (1809-1882), com a teoria de evolução por adaptação às mudanças do ambiente, pela seleção e sobrevivência dos mais aptos. No caso de Darwin, seu procedimento de classificação das espécies foi deturpado ao ser deslocado para outras espécies - as espécies humanas (darwinismo social) -, que passaram a ser rotuladas de degeneradas, psiquicamente pervertidas ou desequilibradas, em oposição aos normais, os desviantes (da curva normal).

Neste período - final do século XIX -, proliferaram desenfreadamente os quadros patológicos e mentais: maníacos, pervertidos, paranóicos, psicopatas, dementes, histéricas, esquizofrênicos, delinquentes, etc. $O$ enquadramento atinge seu ápice de esquadrinhamento (matemático), de extrapolação (matemática) e de normalidade (matemática). Triunfo não apenas dos números e das medidas, mas da estatística, como legitimadora dos padrões de normalidades populacionais.

R. Inter. Interdisc. INTERthesis, Florianópolis, v.11, n.2, p.96-117, Jul-Dez. 2014
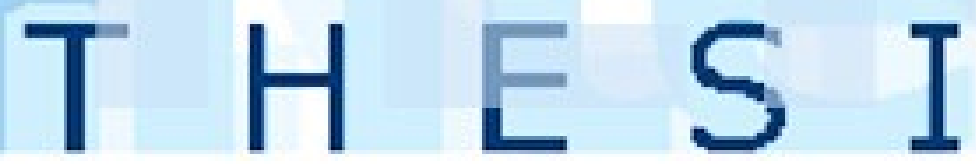
Cabe ressaltar, neste contexto, que a curva exponencial de ascensão populacional como fenômeno social e histórico no século $X X$, consolidou continuidade à era dos dados estatísticos.

Mantendo a linha do raciocínio nesta crítica ao normalizar e normatizar, e aos veredictos dos diagnósticos e suas permanentes marcas, uma excelente reflexão nos apresenta o sociólogo canadense Erving Goffman (1922-1982), no clássico livro Estigma: notas sobre a manipulação da identidade deteriorada, publicado em 1963 nos EUA. Goffman (1988) menciona três tipos de estigmas: as deformidades físicas, as culpas de caráter individual, percebidas como vontade fraca, e os estigmas tribais de raça, nação e religião:

O termo estigma, portanto, será usado em referência a um atributo profundamente depreciativo, mas o que é preciso, na realidade, é uma linguagem de relações e não de atributos. Um atributo que estigmatiza alguém pode confirmar a normalidade de outrem, portanto ele não é, em si mesmo, nem honroso e nem desonroso. [...] $O$ termo estigma e seus sinônimos ocultam uma dupla perspectiva: Assume o estigmatizado que a sua característica distintiva já é conhecida ou é imediatamente evidente ou então que ela não é nem conhecida pelos presentes e nem imediatamente perceptível por eles? No primeiro caso, está-se lidando com a condição do desacreditado, no segundo, com a de desacreditável (GOFFMAN, 1988, p. 13-4, grifos meus).

As contribuições de Goffman são significativas para alinhavar nossas reflexões e inflexões, quando estas implicam distinções sobre os conceitos de normalização e normatização, principalmente no tocante à percepção que um indivíduo tem de si e das ações daí derivadas, quanto à visibilidade do estigma. Ao abordar como cada um concede a sua imagem e como pretende mantê-la para os outros, diferencia normalização de normificação:

As pessoas que têm um estigma aceito fornecem um modelo de "normalização" que mostra até que ponto podem chegar os normais quando tratam uma pessoa estigmatizada como se ela fosse um igual. (A normalização deve ser diferenciada da normificação, ou seja, o esforço, por parte de um indivíduo estigmatizado, em se apresentar como uma pessoa comum, ainda que não esconda necessariamente o seu defeito) (GOFFMAN, 1988, p. 40, grifos meus).

O autor trabalha um tipo especial de normas, as referentes à identidade, de ordem psicológica, e estas normas de identidade engendram tanto desvio quanto conformidade, gerando, desta maneira, manipulações do estigma, num processo de possível controle da informação que o indivíduo transmite sobre si em alinhamentos intragrupais e exogrupais, permitindo voluntariamente exigir ou não uma aceitação. Defende que a manipulação do estigma é uma característica da sociedade, quer

R. Inter. Interdisc. INTERthesis, Florianópolis, v.11, n.2, p.96-117, Jul-Dez. 2014
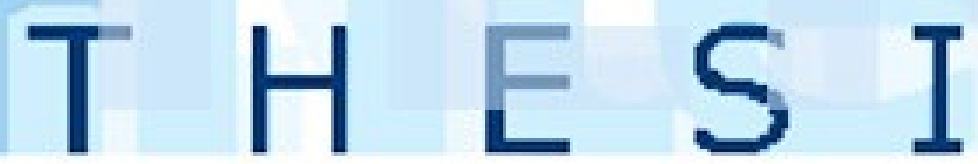
seja uma diferença importante quer uma diferença insignificante. Neste processo, o estigmatizado e o normal têm uma espécie de caracterização mental padrão. É neste contexto individual e social que o sociólogo canadense defende que a pessoa estigmatizada seja chamada de desviante normal, uma unidade eu-outro, normalestigmatizado: "Mesmo quando um indivíduo tem sentimentos e crenças bastante anormais, é provável que ele tenha preocupações normais e utilize estratégias bem normais ao tentar esconder essas anormalidades de outras pessoas [...]" (GOFFMAN, 1988, p.142). Esta afirmação de Goffman auxilia na tentativa de compreender este complexo funcionamento psicossocial, cultural e histórico dos sentimentos atributivos e relacionais de normalidade e anormalidade, seja pelo próprio indivíduo, seja pelo grupo pertencente.

Neste contexto, as elaborações de Canguilhem, Ewald, Foucault e Goffman foram imprescindíveis para articular as argumentações teóricas e críticas deste artigo: o Manual Diagnóstico e Estatístico de Transtornos Mentais, DSM-5, apoiado na lógica estatística-matemática é um dispositivo de quantificação e qualificação de práticas constitutivas de uma métrica binária de normalidade e anormalidade.

\section{CONSIDERAÇÕES FINAIS}

A edição do DSM-5 mantém acesa a polêmica dos diagnósticos psiquiátricos e a sua conturbada interface com os campos da psicologia e da psicanálise. Para além das contradições, ambiguidades e inconsistências de muitos de seus critérios diagnósticos, o documento (e suas codificações numéricas) é utilizado para legitimar atestados médicos-psiquiátricos, avaliações judiciais, afastamentos provisórios ou definitivos do trabalho, validação de incapacidades, justificativas de internações hospitalares, reembolsos de companhias de seguro, indicações de medicamentos, enfim, um leque de destinações atreladas a uma complexa rede de assistência à saúde das pessoas. O DSM-5, juntamente com o CID-10 - Classificação Estatística Internacional de Doenças e problemas relacionados à Saúde, são documentos de classificação, reconhecidos pela OMS - Organização Mundial de Saúde.

Identifica-se, no recém lançado DSM-5, uma "fluidez" nos diagnósticos com amplitude espectral de transtornos mentais, e este alargamento das possibilidades e probabilidades (estatísticas) dos enquadramentos remete inegavelmente a uma

R. Inter. Interdisc. INTERthesis, Florianópolis, v.11, n.2, p.96-117, Jul-Dez. 2014
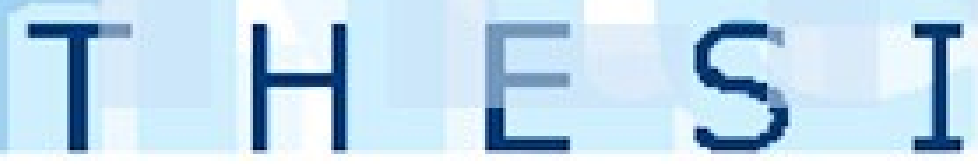
reflexão sobre a incerteza das avaliações fundamentadas em critérios clínicoempíricos. Neste raciocínio, surgem duas questões interligadas e seus riscos inerentes: estaria a Psiquiatria "patologizando" o comportamento normal ou "normalizando" os sintomas patológicos? Descobrindo ou inventando "doenças"?

A questão não é, portanto, científica: a estatística não legitima a ciência, a estatística legitima a representatividade. Se quiséssemos radicalizar, poderíamos argumentar que a própria matemática trabalha com inequações, com números irracionais, números complexos e resultados inexatos. Sendo uma construção humana apropriada por outras construções humanas, não é um modelo de certeza (absoluta?) para as outras ciências imitarem.

As pesquisas e os percentuais estatísticos são terrenos de fácil manipulação, férteis para subterfúgios e erros, não apenas em um mesmo contexto histórico e cultural, mas para análises trans-históricas e/ou anacrônicas, feitas por inferências e extrapolações tendenciosas e perigosas, como se fosse possível e legítimo se apropriar de resultados percentuais de uma época e cultura e aplicá-las em outras.

A crítica, portanto, é para o uso de uma estatística descritiva, aplicada ou convertida em estatística inferencial no campo das ciências humanas.

O uso do argumento da "maioria" para justificar o que um grupo de psiquiatras (da APA) julga ser normal é um argumento basicamente estatístico, que, numa leitura extrapolada e equivocada, converte o comportamento da maioria em certo, em verdadeiro. No máximo, podemos dizer que estes comportamentos normais são mais frequentes ou mais comuns do que aqueles que ficam nos extremos de uma amostra populacional observada. Ainda assim, se convalidarmos o critério estatístico. Mas seus resultados, aceitaremos como parciais e inconclusivos.

O que está em jogo nestes jogos de poder, estatísticos? Descrições se convertendo em prescrições, estas normatizações em normalizações, que configuram verdades. Este é o mecanismo estrutural e funcional das estatísticas, presentes também nas ciências humanas. Estaremos literalmente ou metaforicamente num "jogo de dados", num jogo numérico que ora apropria o ser humano ora o expropria? Dados numéricos, dados estatísticos convertidos em dados normais?

Mas o que é biologicamente normal, culturalmente normal, historicamente normal, psicologicamente normal, juridicamente normal? Nesta tessitura com status

R. Inter. Interdisc. INTERthesis, Florianópolis, v.11, n.2, p.96-117, Jul-Dez. 2014
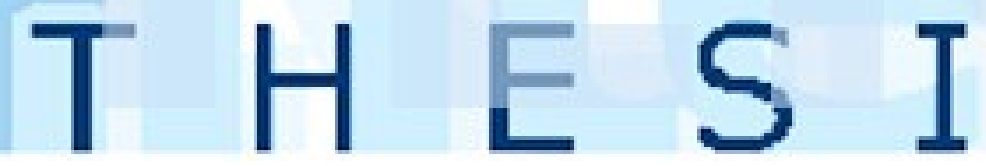
científico (ou pseudocientífico?) se está fragmentando a normalidade? Num jogo de palavras: normal é um adjetivo qualificador (e desqualificador no seu antônimo) ou é um substantivo incorporado/ocultado nos sujeitos, materializado como condição em duas palavras antagônicas, binárias e hierárquicas: os "normais" e os "anormais"?

Poder-se-ia, num primeiro momento, concluir que este texto procurou problematizar a normalidade como critério objetivo e científico; ou, em oposição, a normalidade como um critério subjetivo, o que é normal para mim não o é para o outro. O ponto nodal é a norma-verdade, um casamento entre a normalidade e a verdade, verdade não como conhecimento objetivo ou subjetivo em relação ao pensamento, mas verdade como obrigação de pensar de uma certa maneira, em uma certa época, em determinado lugar, como destaca Foucault em sua produção.

A intenção destas reflexões e inflexões foi apenas denunciar a existência de critérios normativos duvidosos de normalidades gerais e de normalidades específicas, ou até paradoxalmente, normalidades anormais e anormalidades normais. O documento histórico, DSM-5, Manual Diagnóstico e Estatístico de Transtornos Mentais, faz parte destes jogos de poder, psiquiátrico e estatístico.

R. Inter. Interdisc. INTERthesis, Florianópolis, v.11, n.2, p.96-117, Jul-Dez. 2014
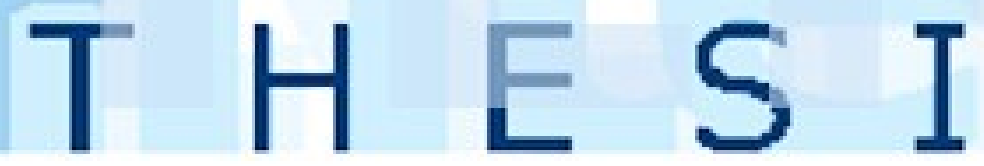


\title{
DIAGNOSTICAL AND STATISTICAL MANUAL OF MENTAL DISORDERS- FIFTH EDITION- DSM-5, STATISTICS AND HUMAN SCIENCES: INFLECTIONS ON NORMALIZATION AND STANDARTIZATION
}

\begin{abstract}
:
The edition of the Diagnostical and Statistical Manual of Mental Disorders - Fifth Edition- DSM-5 in 2013 remains on the controversy about psychiatric diagnoses. The field of psychiatry, historically at odds with psychology and psychoanalysis (as the form evaluation and therapeutic), continues to sustain a classificatory (taxonomic) quadrate practice, based on characteristics and diagnostic criteria of disturbances or verified disorders, mostly empirically. The use of statistical tools in the human sciences is questionable, and what is intended in this article is to point the guise of quantitative criteria in qualitative criteria and, by extension, the common discursive practice of confusing descriptions with appreciations, the latter with evaluative and normative judgments. A circle is closed: the frequencies (statistics) define the normalities (axiological) and these are sustained in frequencies. In this context, the elaborations of Canguilhem, Ewald, Foucault and Goffman were essential to the articulation of critical theoretical arguments.
\end{abstract}

Keywords: DSM-5. Statistical. Human Sciences. Normalization. Normativity

\section{MANUAL DIAGNÓSTICO Y ESTADÍSTICO DE LOS TRASTORNOS MENTALES - DSM-5, ESTADÍSTICAS Y CIENCIAS HUMANAS: INFLEXIONES SOBRE NORMALIZACIÓN Y NORMATIZACIÓN}

\section{Resumen:}

La edición del Manual Diagnóstico y de los Trastornos Mentales - DSM-5 del año 2013 mantiene la controversia sobre los diagnósticos psiquiátricos. El campo de la psiquiatría, históricamente en disputa con la psicología y el psicoanálisis (en cuanto a la forma de evaluación y terapéutica), sigue sosteniendo una práctica de encuadramiento clasificatorio (taxonómica), con base en las características y los criterios de diagnóstico de las perturbaciones 0 trastornos comprobados empíricamente, en su mayoría. El uso de herramientas estadísticas en el ámbito de las ciencias humanas es cuestionable, y lo que se pretende en este artículo es indicar la ocultación de criterios cuantitativos en criterios cualitativos y, por extensión, la práctica discursiva común de confundir las descripciones con las apreciaciones, estas últimas con juicios valorativos y normativos. Se cierra un círculo: las frecuencias (estadísticas) definen las normalidades (axiológica) y éstas se justifican en las frecuencias. En este contexto, las elaboraciones de Canguilhem, Ewald, Foucault y Goffman fueron indispensables para la formulación de los argumentos teóricos críticos.

Palabras clave: DSM-5. Estadística. Ciencias Humanas. Normalización. Normatización. 


\section{REFERÊNCIAS}

AMERICAN PSYCHIATRIC ASSOCIATION. DSM-5 - Manual Diagnóstico e Estatístico de Transtornos Mentais. Porto Alegre: Artmed, 2014.

AMERICAN PSYCHIATRIC ASSOCIATION. DSM-IV - Manual Diagnóstico e Estatístico de Transtornos Mentais. Porto Alegre: Artmed, 2002.

BARBETTA, Pedro Alberto. Estatística aplicada às Ciências Sociais.

Florianópolis: Editora da UFSC, 1998.

BARROS, FISCHER \& Associados. Estatística: parâmetros, variáveis, intervalos, proporções. (série Ciências Exatas n 13). São Paulo: BFA, 2005.

BERTOLOTE, José Manoel. Glossário de Termos de Psiquiatria e Saúde Mental da CID-10 e seus derivados. Porto Alegre: Artes Médicas, 1997.

CANGUILHEM, Georges. O Normal e o Patológico. Rio de Janeiro: Forense Universitária: 1995.

CORDIOLI, Aristides Volpato. Psicofármacos. Porto Alegre, Artes Médicas: 1997.

DANCEY, Christine P. \& REIDY, John. Estatística sem matemática para psicologia. Porto Alegre, Artmed, 2006.

DAVIS, James A. Levantamento de dados em sociologia: uma análise estatística elementar. Rio de Janeiro: Zahar, 1976.

DORSCH, Friedrich. Diccionario de Psicología. Barcelona, Espanha: Editorial Herder, 1978.

DURKHEIM,Emilé. As regras do método sociológico. São Paulo: Martin Claret, 2003.

EWALD, François. Foucault: A Norma e o Direito. Lisboa, Portugal: Vega, 2000.

R. Inter. Interdisc. INTERthesis, Florianópolis, v.11, n.2, p.96-117, Jul-Dez. 2014
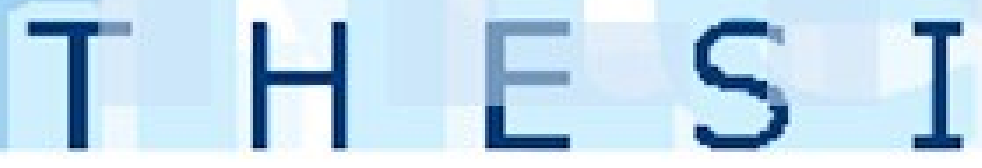
FOUCAULT, Michel. Vigiar e Punir: nascimento da prisão. Petrópolis, RJ, Vozes, 1987.

FOUCAULT, Michel. Doença Mental e Psicologia. Rio de Janeiro: Tempo Brasileiro, 1994.

FOUCAULT, Michel. A arqueologia do saber. Rio de Janeiro: Forense Universitária: 1995.

FOUCAULT, Michel. As palavras e as coisas: uma arqueologia das ciências humanas. São Paulo: Martins Fontes, 1999.

GOFFMAN, Erving. Estigma: notas sobre a manipulação da identidade deteriorada. Rio de Janeiro: Guanabara, 1988.

PONTES, Cleto Brasileiro. Psiquiatria: Conceitos e Práticas. São Paulo: Lemos Editorial, 1998.

WADA, Ronaldo \& VIEIRA, Sônia. O que é Estatística. São Paulo: Brasiliense, 1987.

VIEIRA, Sonia. Introdução à Bio-Estatística. São Paulo: Campus, 1991.

\section{Artigo:}

Recebido em Julho de 2014

Aceito em Outubro de 2014

R. Inter. Interdisc. INTERthesis, Florianópolis, v.11, n.2, p.96-117, Jul-Dez. 2014
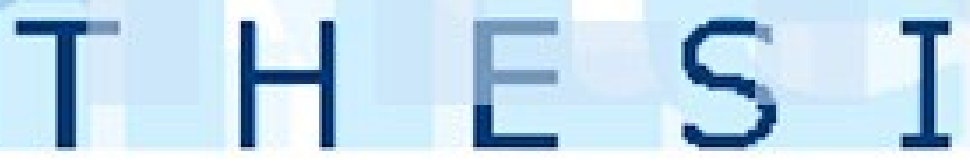